\title{
Employing bacteria machinery for antibiotic detection: Using DNA gyrase for ciprofloxacin detection
}

\author{
Ana R. Cardoso ${ }^{\mathrm{a}, \mathrm{b}, \mathrm{c}}$, Liliana P.T. Carneiro ${ }^{\mathrm{b}, \mathrm{c}}$, Gustavo Cabral-Miranda ${ }^{\mathrm{d}, \mathrm{e}}$, \\ Martin F. Bachmann ${ }^{\text {d,e }}$, M. Goreti F. Sales ${ }^{\text {a,b,c, }}$ \\ a BioMark@UC, Department of Chemical Engineering, Faculty of Science and Technology, Coimbra University, Coimbra, Portugal \\ ${ }^{\mathrm{b}}$ BioMark@ISEP, School of Engineering, Polytechnic Institute, Porto, Portugal \\ ${ }^{\mathrm{c}}$ CEB, Centre of Biological Engineering, Minho University, Braga, Portugal \\ ${ }^{\mathrm{d}}$ Centre for Cellular and Molecular Physiology (CCMP), The Jenner Institute, University of Oxford, Oxford, UK \\ ${ }^{\mathrm{e}}$ Immunology, RIA, Inselspital, University of Bern, Switzerland
}

\section{A R T I C L E I N F O}

\section{Keywords:}

Biochemical target of antibiotics

DNA gyrase

Ciprofloxacin

Screen-printed electrodes

Electrochemical biosensor

Antibodies

\begin{abstract}
A B S T R A C T
This work describes a new successful approach for designing biosensors that detect antibiotics. It makes use of a biomimetic strategy, by employing the biochemical target of a given antibiotic as its biorecognition element. This principle was tested herein for quinolones, which target DNA gyrase in bacteria. Ciprofloxacin (CIPRO) was tested as a representative antibiotic from the quinolone group; the sensitivity of biosensor to this group was confirmed by checking the response to another quinolone antibiotic (norfloxacin, NOR) and to a non-quinolone antibiotic (ampicillin, AMP).

The biorecognition element used was DNA gyrase attached by ionic interactions to a carbon support, on a working electrode on common screen-printed electrodes (SPEs). The response against antibiotics was tested for increasing concentrations of CIPRO, NOR or AMP, and following the subsequent electrical changes by electrochemical impedance spectroscopy. The DNAgyrase biosensor showed sensitive responses for CIPRO and NOR, for concentrations down to $3.02 \mathrm{nM}$ and $30.2 \mathrm{nM}$, respectively, with a very wide response range for CRIPRO, up to $30.2 \mu \mathrm{M}$. Its response was also confirmed selective for quinolones, when compared to its response against AMP. Further comparison to an immunosensor of similar design (adding antibodies instead of DNA gyrase) was made, revealing favourable features for the new biomimetic biosensor with $1.52 \mathrm{nM}$ of limit of detection (LOD).

Overall, the new approach presented herein is simple and effective for antibiotic detection, displaying a selective response against a given antibiotic group. The use of bacterial machinery as biorecognition element in biosensors may also provide a valuable tool to study the mechanism of action in bacterial cells of new drugs. This is especially important in the development of new drugs to fight bacterial resistance.
\end{abstract}

\section{Introduction}

Antibiotics are naturally occurring, semi-synthetic and synthetic compounds with antibacterial activity, typically employed for improving human and animal health [1], as well as for improving feed efficiency and promoting animal/fish growth in farming processes [2,3]. They enabled extending the lifetime of humans/animals, but generated a vicious cycle of an increasing population and an increasing demand for these drugs, both for human and for veterinary purposes [4].

The global antibiotic consumption increased by almost $40 \%$ from
2000 to 2015, corresponding to more than 42 billion daily doses [5]. Estimates indicate that about 106000 tons of antibiotics will be employed by 2030, and from these about one third correspond to the increasing implementation of large-scale intensive farming, in which aquaculture [6] is included, typically employing antimicrobials in subtherapeutic levels [4]. Globally, these antibiotics end up in sewages and wastewater treatment plants, appearing later in large amounts in environmental water, soil and sediments, thereby affecting the surrounding ecosystem $[7,8]$.

When these antibiotics meet bacteria in water bodies, new

\footnotetext{
* Corresponding author at: BioMark Sensor Research/UC, Chemical Engineering Department, Faculty of Sciences and Technology, Coimbra University, Rua Sílvio Lima, Polo II, Coimbra, Portugal.

E-mail address: goreti.sales@eq.uc.pt (M.G.F. Sales).
} 
pathogenic strains are being formed that are resistant to these antibiotics [9]. Their concentrations are low, ranging from ng/L to $\mu \mathrm{g} / \mathrm{L}$, but they compromise the efficiency of antimicrobial therapies by the development of resistant genes $[10,11]$. According to the World Health Organization (WHO), antibacterial resistance is increasing and becoming a global threat to public health $[12,13]$.

Thus, it is urgent to fight antibiotic resistance and this should start by reducing their release into the environment. This requires constant monitoring and controlling of antibiotics in-situ [14], for which low cost biosensors are required. This is mostly valuable and interesting for aquaculture farmers. They may use biosensors to grant that only the minimum amount the antibiotic to terminate the bacterial infection in fish is being employed. This procedure is a win/win scenario that reduces costs of production and prevents additional contamination of environmental waters.

To this end, this work addresses for the first time in the literature a biosensor that uses bacteria machinery to which the antibiotic interacts as a biorecognition element. This was never tried out before for antibiotics and essentially mimics nature. In essence, antibiotics are organic compounds grouped in different classes (Fig. 1), as $\beta$-lactams, sulfonamides, quinolones, aminoglycosides and tetracyclines, according to their chemical structure and mechanism of action $[15,16]$. Antibiotics can inhibit the cell wall synthesis, nucleic acids action, interact with protein synthesis or metabolic pathways, and/or disrupt the bacterial cell membrane [17]. These different actions are related to the different cell targets of the several groups of antibiotics, as shown in Fig. 1. Each of these targets give a clue of a biomolecule to which each antibiotic group holds high and selective affinity. Thus, its use in a biosensor would lead to a selective response against a given group of antibiotics, which would provide valuable information, not only for environmental monitoring, but also for pharmacological and kinetic studies with new drugs under development.

This novel concept was tested herein for quinolones [18,19], a group of synthetic antibiotics that is common in environmental waters [20-22]. Ciprofloxacin (CIPRO) is one of the mostly used quinolones
(Fig. S1), which also displays high stability in soil and wastewater systems $[18,23,24]$. It has been linked to the formation of resistant genes [25], thereby justifying its urgent monitoring. In terms of mechanism, quinolones interfere with bacterial metabolism by interacting with bacterial DNA gyrase [26]. This means that quinolone antibiotics display a high and selective affinity for DNA gyrase, supporting the use of DNA gyrase as a biorecognition element to detect quinolones in biosensors, including CIPRO in particular.

In the literature, biosensors for CIPRO are assembled with conventional biorecognition elements. These include several compounds, as nucleic acid-based biosensors or enzymes/nanoparticles with catalytic activity for CIPRO or antibodies [24,27-32]. Overall, there are no previous works offering a similar approach to the one proposed herein. Yet, it is important to highlight that a biosensor with DNAGyrase as biorecognition element would be responding to the antibiotic group interacting with this bacterial target, and not only to CIPRO The use of bacterial machinery as biorecognition element in biosensors may also provide a valuable tool to study the mechanism of action in bacterial cells of new drugs.

This work reports the immobilization of DNA gyrase on carbon screen-printed electrodes (C-SPEs) modified with carboxylated carbon nanotubes and the evaluation of the resulting electrochemical performance. Carbon nanotubes have been used in commercial SPEs for improving their electrochemical features. These nanomaterials have several electrochemical properties like high surface area, electron-rich properties (faster electron transfer kinetics), low residual current, readily renewable surface [33] and excellent chemical and thermal stability. These features made carbon-based materials very promising nanomaterials in different fields of knowledge [34].

The cross-response to other antibiotics is evaluated and compared with an immunosensor assembled in a similar way. Application to the analysis of spiked waters is also described.

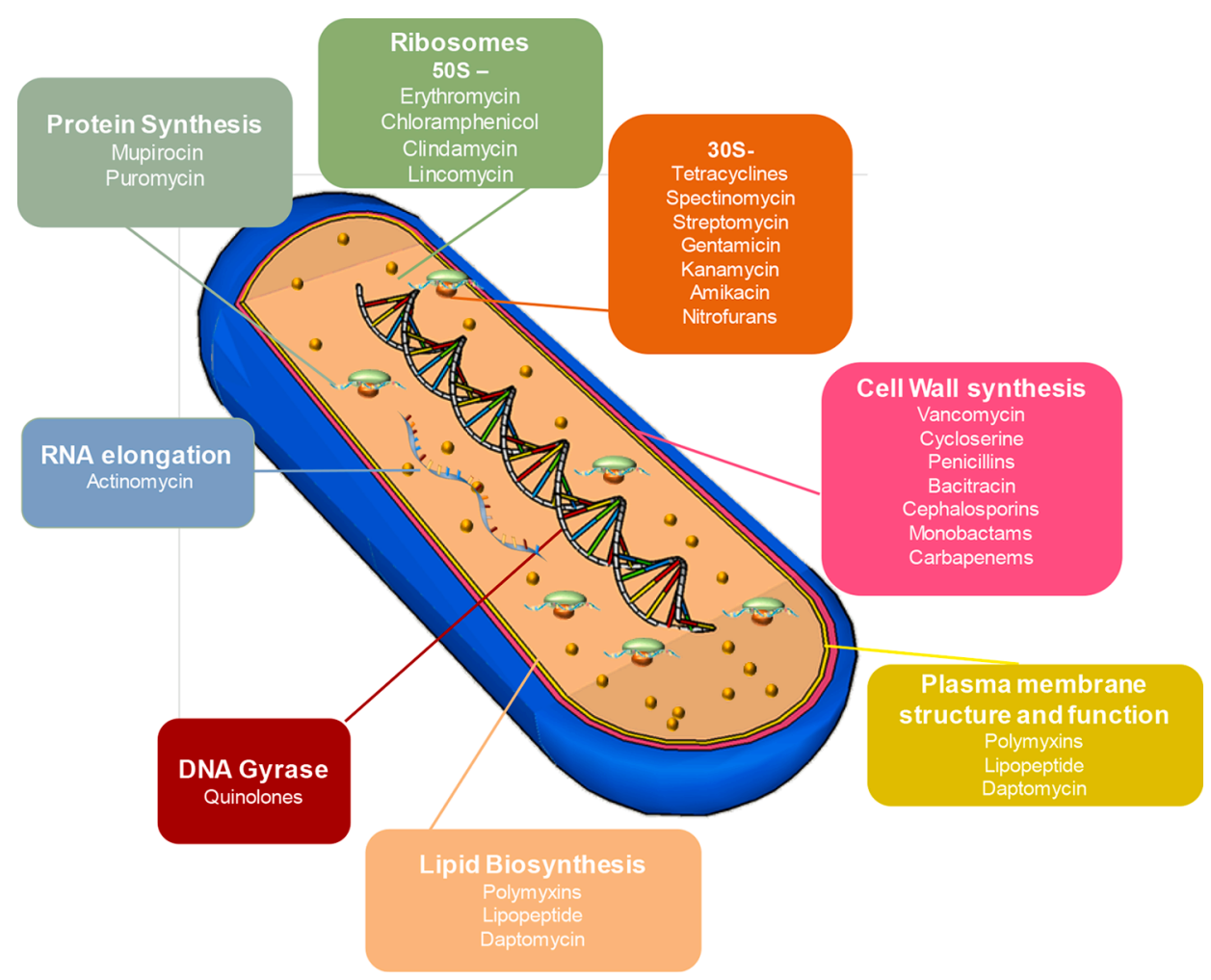

Fig. 1. Overall representation of the different groups of antibiotics and their bacterial cell targets. 


\section{Experimental section}

\subsection{Apparatus}

Electrochemical readings were made in a potentiostat/galvanostat/ impedance analyzer from PalmSens4, controlled by PSTrace electrochemistry software. C-SPEs were purchased from Metrohm (DRP-110), which contained carbon counter and auxiliary electrodes and a silver pseudo-reference electrode printed on a ceramic substrate of $3.4 \times 1.0$ $\times 0.05 \mathrm{~cm}$ dimensions; the carbon-working electrode had $4 \mathrm{~mm}$ diameter. C-SPEs were linked to the potentiostat via a switch box produced by EIH/Porto-Portugal.

Raman spectra were collected in a Raman DXR from Thermo Scientific, equipped with confocal microscopy. A $532 \mathrm{~nm}$ laser was employed, at a maximum power of $5 \mathrm{~mW}$, operating with a $50 \mu \mathrm{m}$ slit, a spot size of $0.5 \mu \mathrm{m}$ and a resolution of $5.5-8.3 \mathrm{~cm}^{-1}$.

\subsection{Reagents and solutions}

Ultrapure Milli-Q water laboratory grade (conductivity $<0.1 \mu \mathrm{S} / \mathrm{cm}$ ) was used throughout. The chemical reagents used include potassium hexacyanoferrate III $\left(\mathrm{K}_{3}\left[\mathrm{Fe}(\mathrm{CN})_{6}\right]\right)$, potassium hexacyanoferrate II $\left(\mathrm{K}_{4}\left[\mathrm{Fe}(\mathrm{CN})_{6}\right]\right)$ trihydrate and sodium acetate, from Riedel-deHäen; $p$ phenylenediamine, carboxylated carbon nanotubes, CIPRO and norfloxacin, from Sigma-Aldrich; $N^{\prime}$-ethyl- $N^{\prime}$-(3-dimethylaminopropyl)carbodiimide hydrochloride (EDAC) and ampicillin (AMP), from Alfa Aesar; $N$-hydroxysuccinimide (NHS), from Fluka; $N$-dimethylformamide (DMF) and acetic acid, from Analar Normapur; phosphate buffer saline (PBS) and bovine serum albumin (BSA), from Amresco; DNA gyrase and anti-enrofloxacin/CIPRO (Ab-ENRO/CIPRO) were obtained from Santa Cruz Biotechnology.

All solutions were prepared in 0.1 M PBS solution, prepared by dissolving a commercial tablet in ultrapure water. An amount of about $1.00 \mathrm{mg}$ of carboxylated carbon nanotubes was suspended in $1.0 \mathrm{ml}$ DMF. The EDAC/NHS modification used $0.28 \mathrm{mg} / \mathrm{ml}$ EDAC and 0.70 $\mathrm{mg} / \mathrm{ml}$ NHS solutions, freshly prepared in PBS. A $0.020 \mathrm{M} p$-phenylenediamine solution and $0.50 \mathrm{mg} / \mathrm{ml}$ were prepared in PBS. The electrical changes were followed by a solution with $5.0 \times 10^{-3} \mathrm{M} \mathrm{K}_{3}[\mathrm{Fe}$
$\left.(\mathrm{CN})_{6}\right]$ and $5.0 \times 10^{-3} \mathrm{M} \mathrm{K}_{4}\left[\mathrm{Fe}(\mathrm{CN})_{6}\right]$, prepared in PBS, pH 7.40. The different standards were prepared in $0.1 \mathrm{M}$ acetate buffer with $\mathrm{pH} 4.00$. The Gyrase Reaction Buffer (commercial) was composed of $35 \mathrm{mM}$ Tris$\mathrm{HCl}, 24 \mathrm{mM} \mathrm{KCl}, 4 \mathrm{mM} \mathrm{MgCl}$, $2 \mathrm{mM}$ DTT, $1.75 \mathrm{mM}$ ATP, $5 \mathrm{mM}$ spermidine, $0.1 \mathrm{mg} / \mathrm{ml} \mathrm{BSA}$, and $6.5 \%$ glycerol $\mathrm{pH}$ 7.50. The BSA solution was composed of BSA and PBS.

\subsection{Preparation of electrochemical sensor on carbon screen-printed electrodes}

The assembly of the sensor using antibiotic machinery was based on our previous works regarding the detection of circulating antibodies for Malaria [35] and Zika [36], in which a simple approach was included to immobilize the target antigens. Herein, the biorecognition element bound to the electrode was DNA gyrase, and antibodies were also used but for comparison purposes.

In detail, C-SPEs were modified as described in Fig. 2. First, carboxylated carbon-nanotubes in DMF were dispersed and incubated in the working electrode $\left(72{ }^{\circ} \mathrm{C}\right.$, for $\left.30 \mathrm{~min}\right)$. Then, the carboxylic groups of the carbon nanotubes were activated by incubating EDAC/NHS solutions, freshly mixed, for $1 \mathrm{~h} 30 \mathrm{~m}$, at room temperature. The next step consisted in the incubation of $p$-phenylenediamine $(0.02 \mathrm{M})$, for $1 \mathrm{~h}$, at room temperature, to form an amine layer.

The biorecognition element was added by incubating the DNA gyrase solution $(1 \mu \mathrm{l}$ of DNA gyrase $+6 \mu \mathrm{l}$ DNA gyrase reaction buffer $+23 \mu \mathrm{l}$ $\mathrm{PBS}$ ), for $30 \mathrm{~min}$, at room temperature. When antibodies were employed, a solution of Ab-ENRO/CIPRO $(0.1 \mathrm{mg} / \mathrm{ml})$ was incubated (instead of DNA gyrase), for $30 \mathrm{~min}$, at $37^{\circ} \mathrm{C}$. Non-specific binding to the antibodies was avoided by incubating next a BSA solution, for $1 \mathrm{~h}$, at $4{ }^{\circ} \mathrm{C}$ [37].

Each step of the assembly of the biosensor (immobilization of carbon nanotubes, incubation with EDAC/NHS, p-phenylenediamine and DNA Gyrase or antibodies) was followed by washing with Milli-Q water and drying with nitrogen.

The binding of CIPRO was made by incubating standard solutions of increasing concentrations. Each standard was let stand for $30 \mathrm{~min}$ at room temperature, and then this solution was washed out and replaced by the iron redox probe to collect the electrochemical data. All assays

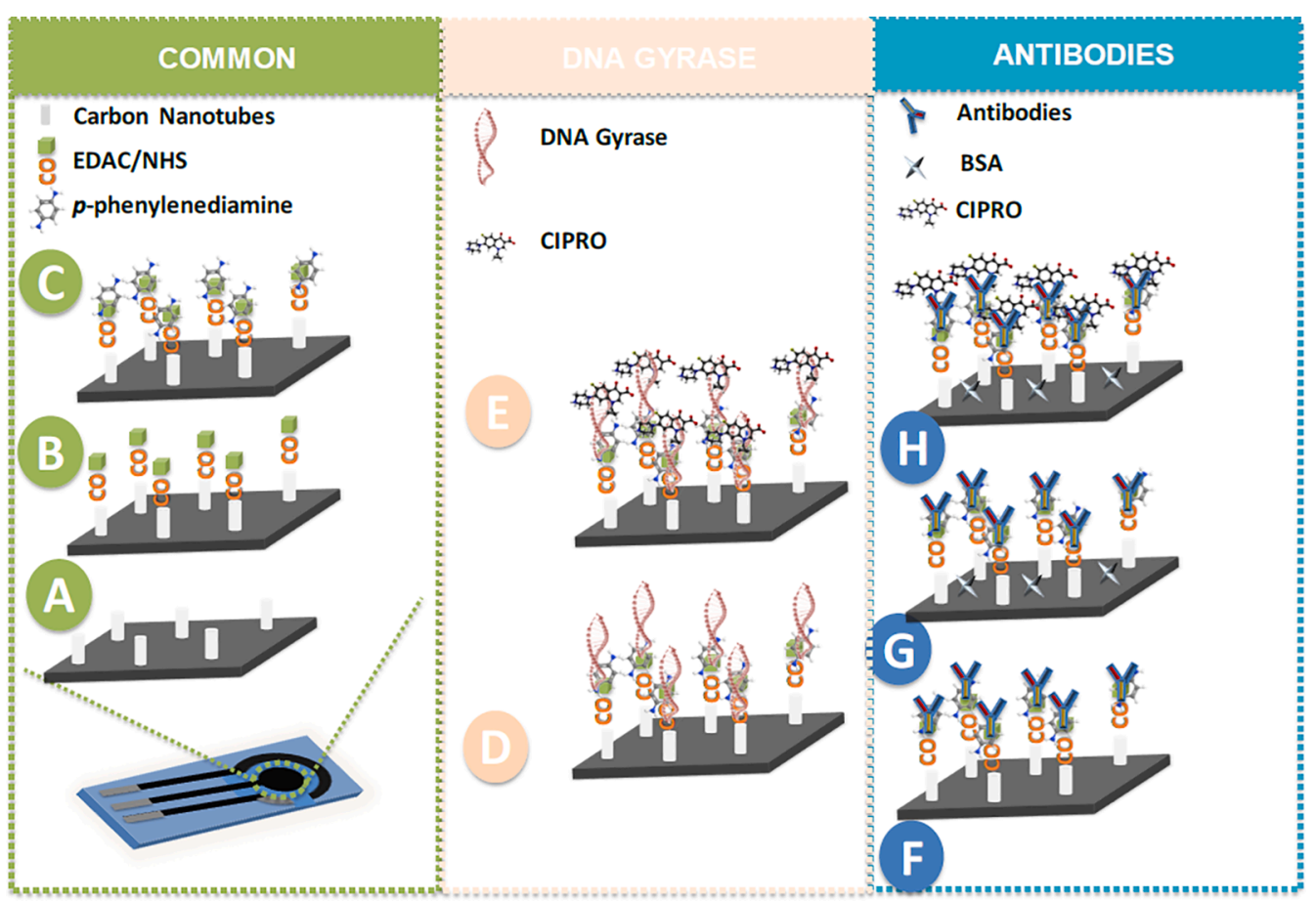

Fig. 2. Schematic representation of the modification of the C-SPEs. It starts by a common approach by (A) adding carboxylated carbon nanotubes, (B) modifying these with EDAC/NHS and (C) inactivating active carboxyl groups with $p$-phenylenediamine. DNA gyrase biosensors are prepared by additional incubation of (D) DNA-gyrase for subsequent (E) CIPRO binding. When antibodies are intended as biorecognition, the assembly continues after stage (C) with the incubation of (F) antibodies, followed by (G) BSA incubation to block non-specific binding and (H) CIPRO binding. 
were performed in triplicate.

\subsection{Electrochemical procedures}

The electrochemical studies involved Cyclic Voltammetry (CV), Electrochemical Impedance Spectroscopy (EIS) and Square Wave Voltammetry (SWV) assays, performed with the iron redox probe solution incubated in the 3-electrode system. CV assays were made by scanning potentials from -0.3 to $+0.7 \mathrm{~V}$, at $50 \mathrm{mV} / \mathrm{s}$. EIS assays used a sinusoidal potential perturbation with amplitude $0.01 \mathrm{~V}$, and 50 frequency values, logarithmically distributed from 0.1 to $100,000 \mathrm{~Hz}$. The EIS data was fitted to a Randles equivalent circuit using 5.5 PSTrace from PalmSens and was analyzed by Nyquist plot. SWV assays were conducted from -0.3 to $+0.7 \mathrm{~V}$, with a frequency of $25 \mathrm{~Hz}$ and the step height of to 50 $\mathrm{mV}$.

Concerning the EIS data, Nyquist plots were used, showing the negative imaginary impedance $-Z^{\prime \prime}$ versus the real part of the impedance $\mathrm{Z}^{\prime}$ [38]. This circuit contained $\mathrm{R}_{\mathrm{ct}}, \mathrm{C}_{\mathrm{dl}}$ and $\mathrm{Z}_{\mathrm{w}}$ elements that represent, respectively, charge transfer resistance, double layer capacitance and Warburg impedance. The $R_{c t}$ value is extracted by measuring the diameter of the semicircle, providing information about the difficulty of electron transfer of the ferro/ferricyanide redox probe between the solution and the electrode surface [39].

The limit of detection (LOD) was calculated as $\mathrm{X}+3 \sigma$, where $\mathrm{X}$ was the average value of the EIS blank signals (obtained in the absence of CIPRO) and $\sigma$ the known standard deviation of EIS blank signal in consecutive readings [40].

\section{Results and discussion}

\subsection{Assembly the DNA gyrase biosensor}

The sequential chemical modifications made on the working electrode (Fig. 2) changed the typical electron transfer properties of the 3electrode system. These properties were monitored by following the response of a standard iron probe, in CV, EIS and SWV electrochemical techniques (Fig. 3), which were also used to confirm the success of such modifications. The corresponding electrochemical data may be seen in Table 1.

The first stage consisted in the incubation of carboxylated carbon nanotubes (Fig. 2A). Typically, the addition of carbon nanotubes leads to a significant increase of the current signals, although the presence of carboxyl functions diminishes the conductivity features of these nanomaterials, because the alternated $\pi$ electron signature has several interruptions along their way. Thus, the changes observed in terms of electrochemical performance (Fig. 3) evidenced higher currents in CV

Table 1

Average values of the electrochemical data obtained in each step of the assembly of the biosensor, detailing CV, EIS and SWV generated data.

\begin{tabular}{|c|c|c|c|c|c|c|}
\hline \multirow{2}{*}{$\begin{array}{l}\text { Steps of } \\
\text { Assembly }\end{array}$} & \multicolumn{4}{|c|}{$\mathrm{CV}$ data } & \multirow{2}{*}{$\begin{array}{l}\text { EIS } \\
\text { data } \\
\mathrm{R}_{\mathrm{ct}} \\
(\Omega)\end{array}$} & \multirow{2}{*}{$\begin{array}{l}\text { SWV data } \\
\text { Peak Height } \\
(\mu \mathrm{A})\end{array}$} \\
\hline & $\begin{array}{l}I_{p, c} \\
(\mu A)\end{array}$ & $\begin{array}{l}I_{p, a} \\
(\mu A)\end{array}$ & $\begin{array}{l}E_{\max } \\
(V)\end{array}$ & $E_{\min (V)}$ & & \\
\hline $\begin{array}{l}\text { Pristine } \\
\text { Electrodes }\end{array}$ & 117 & 121 & 0.240 & -0.008 & 421 & 50.0 \\
\hline $\begin{array}{l}\text { Carbon } \\
\text { nanotubes }\end{array}$ & 125 & -127 & 0.240 & 0.045 & 53 & 79.8 \\
\hline EDAC/NHS & 101 & -102 & 0.240 & 0.005 & 173 & 47.9 \\
\hline DNA Gyrase & 91 & -90 & 0.297 & 0.023 & 336 & 38.1 \\
\hline
\end{tabular}

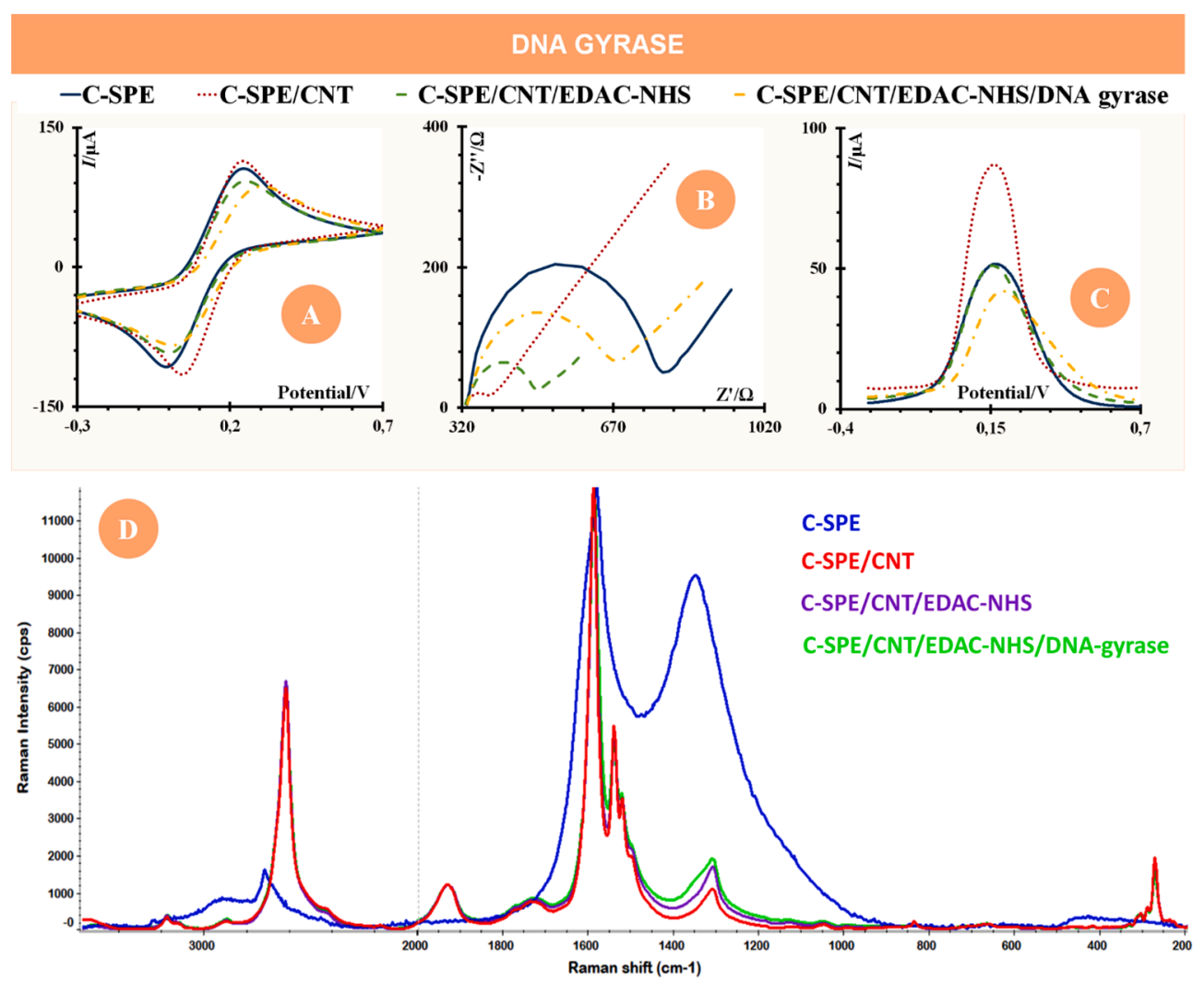

Fig. 3. Electrochemical CV (A), EIS (B), and SWV (C) follow-up of the sequential modification of the C-SPEs (layers of carboxylated nanotubes, EDAC/NHS, and DNA gyrase), along with the Raman spectra for these layers, normalized to G-band and recorded in a later stage (single-wall carbon nanotubes in D are from a different batch than in A-C). 
around $\pm 125 \mu \mathrm{A}$ and SWV around $\pm 79.8 \mu \mathrm{A}$ and lower Rct values (in EIS) around $53 \Omega$, being this difference more evident in SWV and EIS (Table 1).

The second stage was the activation of carboxylic groups with EDAC reaction to create a highly reactive $O$-acylisourea intermediate that subsequently reacted with NHS (Fig. 2B). This modification was linked to decreasing currents in CV $( \pm 101 \mu \mathrm{A})$ and in SWV $( \pm 47.9 \mu \mathrm{A})$ and increasing $\mathrm{R}_{\mathrm{ct}}$ in EIS (173 $\Omega$ ), as an outcome of the introduction of a nonconductive polar group. The intermediate underwent a mild reaction with an amine group (Fig. 2C), including that from $p$-phenylenediamine, to generate an amined layer on top of the electrode [41].

The biorecognition element DNA gyrase (Fig. 2D) was placed on the amine layer by direct incubation. In general, amine surfaces are a good support for protein binding [42]. In the particular case of DNA gyrase, its isoelectric point is 6.8 meaning that negative charges are dominant at $\mathrm{pH} 7.4$ (but not very intense) and these charges may undergo ionic interactions with the positively charged amine groups. The presence of DNA gyrase on the electrodes yielded lower currents in CV $( \pm 91 \mu \mathrm{A})$ and SWV $(38.1 \mu \mathrm{A})$ and higher Rct values (336 $\Omega$ ) than the EDAC/NHS stage (Fig. 3 and Table 1), but as the effect of the addition of $p$-phenylenediamine was not monitored (this monitoring interacted negatively with the electrode assembly), this direct comparison to the previous stage cannot be made.

Combining all electrochemical data collected herein (CV, EIS and SWV) Table 1, the changes in Rct were clearly more sensitive. Thus, EIS was employed in subsequent studies that involved the incubation of CIPRO (Fig. 2E, H) to assess its binding features in the form of calibrations.

The chemical modification of the several stages of the electrode assembly were also followed by Raman spectroscopy. The C-SPE had a spectra of low intensity with typical $\mathrm{G}^{\prime}$ and $\mathrm{D}$ bands, located at 1581.7 $\mathrm{cm}^{-1}$ and $1347.5 \mathrm{~cm}^{-1}$, respectively. Typically, these correspond, respectively, to the tangential stretching mode from graphitic-like materials and the structural defects in the graphitic $\mathrm{sp}^{2}$ system. The casting of nanotubes (single-walled) on this support that were well dispersed changed dramatically the Raman spectra. The $\mathrm{G}$ and $\mathrm{D}$ bands were now located at 1589.9 and $1310.3 \mathrm{~cm}^{-1}$, with the D-band decreasing significantly, and a G band becoming evident, at $2619 \mathrm{~cm}^{-1}$. Overall, this confirmed the presence of the nanotubes on the C-SPE [43]. The subsequent addition of the EDAC/NHS and DNA-gyrase did not show a significant effect, but indicated a moderate increase of the D-band (relatively to the G-band) that signaled a disordered carbon structure (as expected). This D-band was now located at 1309.2 and $1308.6 \mathrm{~cm}^{-1}$, respectively. Overall, the Raman spectra confirmed the chemical modifications occurring at the electrode surface.

\subsection{Electrochemical response to ciprofloxacin}

The analytical performance of the DNA gyrase biosensor was followed by casting on the working electrode increasing concentrations of CIPRO standard solutions, for $30 \mathrm{~min}$. These solutions ranged from $0.302 \mathrm{nM}$ to $3.02 \mathrm{mM}$. After each antibiotic incubation, the electrodes were washed and the electrical performance measured by EIS, covering the 3-electrode system with the standard iron redox probe. The obtained data is shown in Fig. 4, fitted to a Randles equivalent circuit that was composed by the resistance of the solution (Rs), the double layer capacitance (Cdl), the charge-transfer resistance (Rct) at the electrode surface and the Warburg element (W) signalling diffusion.

Overall, a comparison of all data from the Randles circuit (Table S1) indicated that Rct was the dominant variable changing with CIPRO concentration, and increasing concentrations of CIPRO yielded increasing Rct values (Fig. 4A). This derived from two main aspects. The most significant one is related to the non-conductive features of CIPRO, which contributed to hinder the charge-transfer properties of the sensing layer. The other was much less relevant and accounted the negative protonation of some CIPRO species that may exist $\mathrm{pH} 7.4$, which would contribute for an electrical reduction of the charge transfer ability of the negatively charged iron redox probe. In general, it is likely that most of CIPRO species are in zwitterionic form at $\mathrm{pH} 7.4$ and this is why this effect of the charge change is small.

The increasing Rct values exhibited a linear trend against the logarithm CIPRO concentration, with an average slope of $55.2 \Omega$ /decade concentration and a minimum squared correlation coefficient of 0.998 , from $3.02 \mathrm{nM}$ to $0.302 \mathrm{mM}$ (Fig. 4B). Higher concentrations saturated the response of the sensing layer, while lower concentrations lead to a response that was similar to the blank. The reproducibility of the electrochemical response was excellent, evidencing that the system is reproducible considering that RSD values ranged from $2.12,2.6 \%$ and $0.85 \%$, in $3.02 \mathrm{nM}, 3.02 \mu \mathrm{M}$ and $0.302 \mathrm{mM}$, respectively.

The response of the DNA gyrase biosensor also compares favourably to other biosensors reported in the literature [44-46]. The limit of detection of the DNA gyrase biosensor is $1.52 \mathrm{nM}$ In addition, the

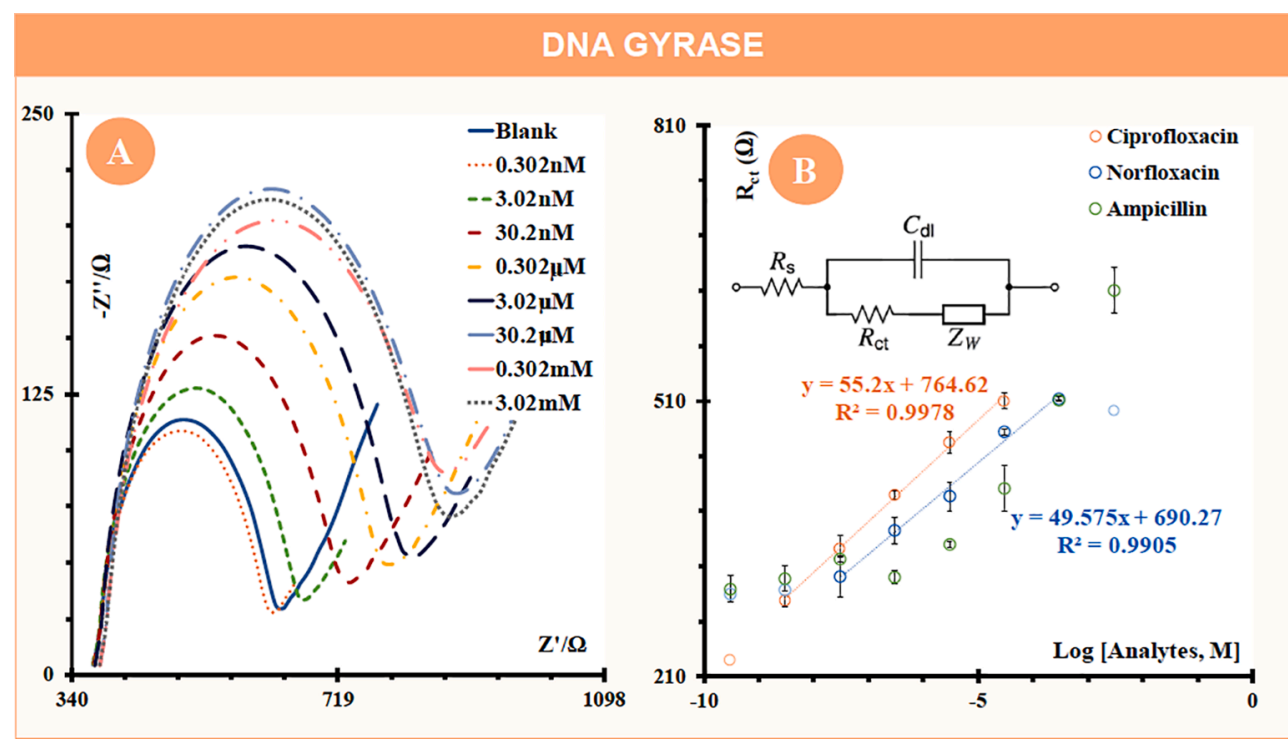

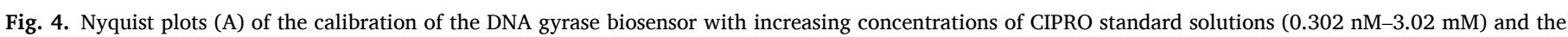

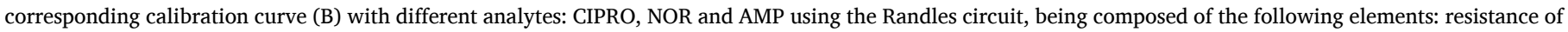

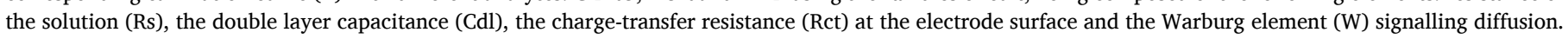


construction of this biosensor is also simpler, when compared to other works, typically requiring several nanomaterials.

\subsection{Electrochemical response to other quinolone}

To response of the DNA gyrase biosensor was tested against another quinolone, to check its ability to respond to the quinolone, as expected when the mechanism of action of antibiotics is considered. Norfloxacin (NOR) was selected for this purpose, a commonly used fluoroquinolone antibacterial agent. The calibration was made as previously described for CIPRO, incubating NOR standard solutions of increasing concentrations for $30 \mathrm{~min}$, and reading the EIS response in the presence of a standard iron redox probe.

In general, the Nyquist plots evidenced increasing Rct values for increasing NOR concentrations (Fig. S2). The diameter of the semicircles increased after $30.2 \mathrm{nM}$, and lower concentrations lead to slight changes in the Rct values. The linear trend against the logarithm concentration of NOR has an average slope of $49.6 \Omega$ /decade concentration and a minimum squared correlation coefficient of 0.9905 , from $30.2 \mathrm{nM}$ to 0.302 $\mathrm{mM}$. Higher concentrations were tested, but the signal reached a saturation after $0.302 \mathrm{mM}$ (Fig. 4C). For calibrations produced with different biosensing units, the standard solutions yielded reproducible data, considering that RSD values were $3.9,3.7 \%$ and $0.64 \%$, for $0.302,3.02$ and $30.2 \mu \mathrm{M}$, respectively.

Comparing to CIPRO, the response of DNA gyrase to NOR was controlled for standard solutions that were $100 \times$ more concentred and underwent a saturation of the electrical signal at the same concentration level. In addition, the sensitivity of the response was about $89 \%$ of the response obtained for CIPRO. Thus, it was logical to assume that CIPRO displayed higher affinity to DNA gyrase then NOR. Interestingly, this is indeed consistent with the clinical treatments applied with these antibiotics. Although this depends on the bacterial strain and target application, CIPRO may be used to treat urinary infections in short (3-day) periods and this is equally effective to longer treatments (7-day) with NOR [47].

\subsection{Electrochemical response to a non-quinolone antibiotic}

In principal, the DNA gyrase biosensor is selective to quinolones, as this biological component of bacterial cells is their target. Thus, if a nonquinolone antibiotic compound is incubated on the sensing layer, it is expected that none or little binding may occur. To confirm this possibility, the DNA gyrase biosensor was calibrated against AMP. This was done using the same conditions reported before for CIPRO and NOR calibrations.

In general, EIS measurements (Fig. S3) evidenced negligible $\mathrm{R}_{\mathrm{ct}}$ changes for concentrations up to $30.2 \mu \mathrm{M}$. This confirmed the small affinity of AMP for DNA gyrase, as expected. Only concentrations higher than $0.302 \mathrm{mM}$ were able to promote significant $\mathrm{R}_{\mathrm{ct}}$ changes, greater than $476.65 \Omega$. Moreover, the response in the lower concentration range where no significant increase was observed was quite table. It showed relative standard deviation values of $4.2,2.4 \%$ and $0.96 \%$, for $3.02 \mathrm{nM}$, $0.302 \mu \mathrm{M}$ and $3.02 \mu \mathrm{M}$, respectively. Overall, this supported its little effect of AMP in the range of concentration where CIPRO was responding (but AMP was not). Within the concentration range studied, no evidence of a linear response was observed for AMP.

In practical terms, it was a fact that for high concentration of AMP the signal of the biosensor increased, meaning that this may be translated by a low concentration of CIPRO. To ensure that CIPRO is being read, it is important that two dilutions of the same sample are tested. If these differently diluted samples give rise to the same concentration in the original sample, than the slope of the calibration is corresponding to CIPRO. If the concentrations are too different, then another antibiotic may be involved in this analysis. In a completely different perspective, if the practical application for this biosensor would be to ensure that low levels of antibiotics are present in the waters, it is a good perspective that other antibiotics may be translated by the biosensor, even with smaller affinity and lower slopes.

Overall, the response of the DNA gyrase biosensor against AMP confirmed the little affinity of DNA gyrase for AMP, while supporting the good selectivity of the electrochemical response for quinolones. The selectivity of the biosensor is addressed next.ure.

\subsection{Selectivity of the DNA gyrase biosensor}

Considering the responses obtained for CIPRO, NOR and AMP, it was possible to estimate the selectivity of the response of the DNA gyrase biosensor against the different antibiotics, from quinolones or nonquinolones. The relative responses of the electrodes to different concentrations are shown in Fig. 5. It confirms the good affinity of CIPRO and NOR to a DNA gyrase surface $(0.302 \mu \mathrm{M}$ and $30.2 \mu \mathrm{M})$, displaying similar sensitivity. This behaviour was clearly different from that of AMP, because this antibiotic is targeting the bacterial cell wall and, apparently, it does not have great affinity to DNA gyrase. Its response was also less reproducible.

Urea and histamine were also tested as these may be present in contaminated waters. The signal produced by these species was very small, decreasing the blank signal by $8-10 \%$. This indicated their small interfering effect upon the biosensor response. It is important to note that the tests made to monitor the affinity of urea and histamine for DNA gyrase had no competition between the main target analyte, which is CIPRO, and the interfering species. This suggests that in a real scenario, where the several species are competing for the same binding target, this interfering effect should be even smaller. Overall, the results obtained confirmed the good selectivity of the response of the biosensor.

\subsection{Comparison to an immunosensor}

As the DNA gyrase serves as a quantitative tool for members of the quinolone family, the quantitative determination of a single element of this family may require another approach. To provide this specific tool for CIPRO in this work, an immunosensor was prepared similarly, by

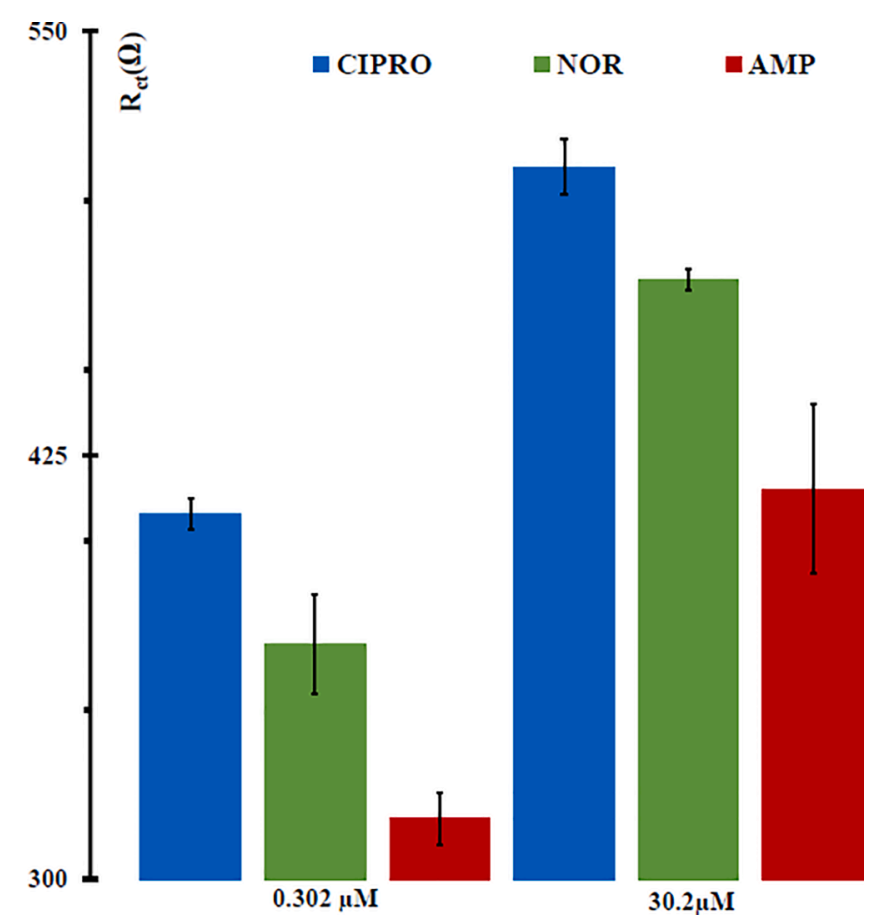

Fig. 5. The absolute Rct values of the DNA gyrase biosensor obtained for the several antibiotics tested herein, in two concentration levels $(0.302 \mu \mathrm{M}$ and $30.2 \mu \mathrm{M})$. 
binding antibodies to the electrode surface instead of DNA gyrase. The antibodies used to this end were Ab-ENRO/CIPRO, as commercially available (no specific Ab-CIPRO was available). In brief, this was done by incubating the antibodies on the amine layer (Fig. 2F, as for the DNA gyrase) and adding BSA after to block non-specific binding (Fig. 2G), as typically done in other immunosensors [48]. The electrochemical data obtained throughout the chemical modifications involved in the assembly of the immunosensor is presented in Fig. S4 and confirm the successful modification of the carbon surface.

In order to establish a straight comparison with the DNA gyrase biosensor, this immunosensor was calibrated against CIPRO, NOR and AMP standard solution, under the same conditions use before. The results obtained are detailed next.

\subsubsection{Electrochemical response to Ciprofloxacin}

The EIS data produced by the incubation of CIPRO standard solutions on the immunosensor is detailed in Fig. 6. As expected, the Rct values increased for increasing concentrations, in a similar behaviour to that of the DNA gyrase biosensor (Fig. 6A). The sensitivity obtained for this response was also similar, equal to $55.6 \Omega$ /decade concentration, with average squared correlation coefficients of 0.999 . The linear response range was however narrower than that observed for the DNA gyrase biosensor, yielding linear responses from $30.2 \mathrm{nM}$ to $0.302 \mathrm{mM}$ (Fig. 6B). As in previous studies, the data obtained herein was reproducible, considering that RSD values were 1.19, 2.30 and $3.06 \%$, in 30.2 $\mathrm{nM}, 0.302 \mu \mathrm{M}$ and $3.02 \mu \mathrm{M}$, respectively. The LOD of the immunosensor was $11.3 \mathrm{nM}$.

This response indicated that the DNA gyrase biosensor had similar sensitivity to the corresponding immunosensor and was able to show a linear response from lower concentrations.

\subsubsection{Electrochemical response to norfloxacin}

The EIS data obtained with NOR standard solutions is shown in Fig. S5 and was less sensitive than that obtained with CIPRO. This was as expected because antibodies were employed. However, it is important to highlight that the antibodies used herein were polyclonal and developed against enrofloxacin and ciprofloxacin, as obtained commercially. This meant that there could be a cross-response to other quinolone structure, as CIPRO, NOR and ENRO have significant structural similarities. Indeed, this was what happened, considering that the Rct increased slightly after incubating NOR, providing an average slope of 45.68
$\Omega /$ decade (Fig. S5B) and an average squared correlation coefficient of 0.9619 . The linear response was however narrower, ranging from 30.2 $\mathrm{nM}$ to $30.2 \mu \mathrm{M}$ and RSD values obtained were 1.35 and $4.40 \%$, in 30.2 $\mathrm{nM}$ and $0.302 \mu \mathrm{M}$, respectively.

\subsubsection{Electrochemical response to a non-quinolone antibiotic}

The electrochemical response of the immunosensor against AMP is shown in Fig. S6A. It evidenced a slight response to AMP and a random response in the higher concentration level. This slight tendency to respond at lower concentrations was unexpected.

To understand if this could be an adsorption to BSA, which was on the electrode surface to reduce non-specific binding, another immunosensor was prepared without BSA coverage. The results of EIS measurements evidenced a more intense response to the highest AMP concentrations (Fig. S6B), having steady signals at the lower concentration level. Indeed, this result confirmed that the BSA was capable to reduce non-specific binding, because it reduced side-responses to higher concentrations, but it could also be responsible for the slight adsorption of AMP at the low concentration level, because without BSA there was no drift observed. Overall, when the surface was without BSA the drift in the lower concentration range was absent, but when BSA was present there was a slight drifting response to positive Rct changes. This would account the fact that when the surface was covered with BSA there was a huge amount of BSA when compared to the binding positions at the antibodies, which magnifies the effect of AMP adsorption to BSA. After saturation of the possible adsorption sites, the signal becomes random.

Of course, there was always the possibility of a slight cross-response of the antibody because CIPRO, NOR and AMP have simple chemical structures (Fig. S1), with a common carboxylic function. Yet, under $\mathrm{pH}$ 4, CIPRO and NOR have carboxyl groups that are mainly neutral, while AMP has this group mainly negatively charged.

Interestingly, the slight drift caused by AMP was not observed in the DNA gyrase sensing, making the DNA gyrase biosensor an excellent way to monitor antibiotics of the quinolone group.

\section{Conclusion}

A novel sensor for CIPRO detection was successfully developed, by employing as biorecognition element its biological target in bacteria, immobilizing DNA gyrase on the working electrode of C-SPEs modified with carboxylated carbon nanotubes. Comparing to other works,

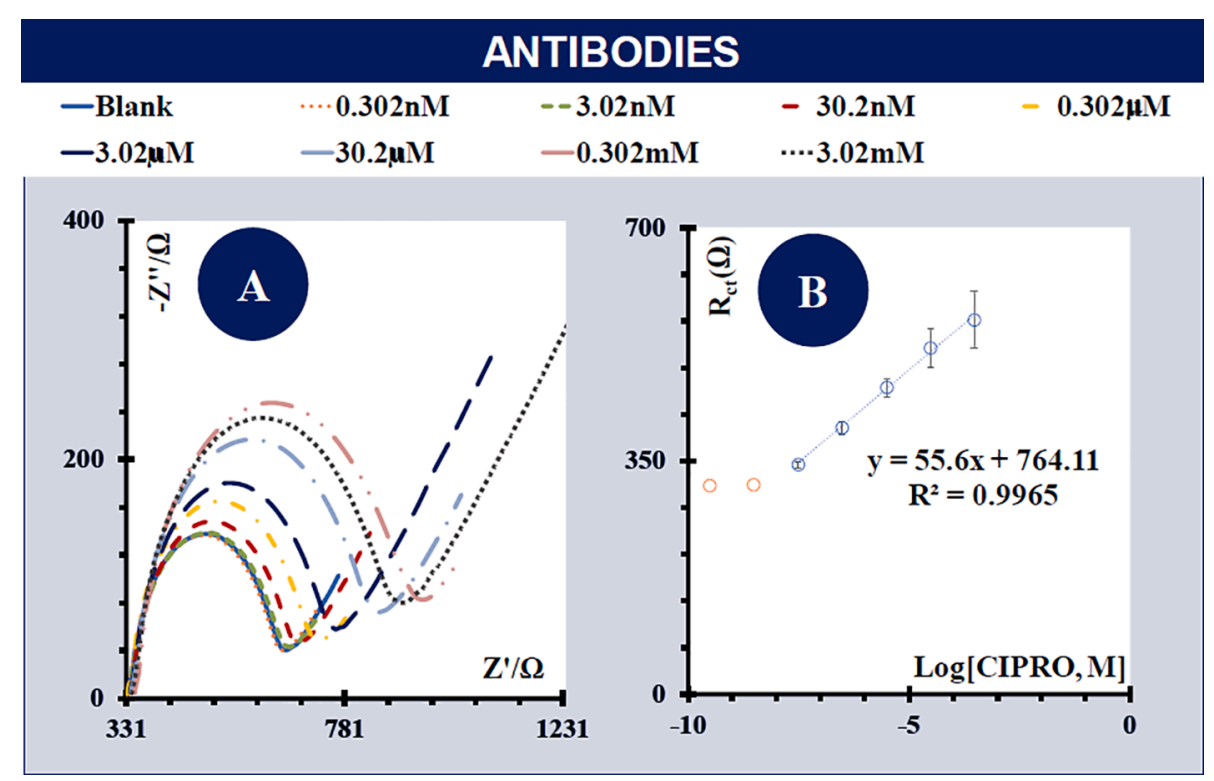

Fig. 6. Nyquist plots (A) of the redox probe $5.0 \times 10^{-3} \mathrm{M}\left[\mathrm{Fe}(\mathrm{CN})_{6}\right]^{3-} /\left[\mathrm{Fe}(\mathrm{CN})_{6}\right]^{4-}$ read in DNAG gyrase biosensors that were incubated for 30 min in CIPRO standard solutions of increasing concentrations, prepared in $0.1 \mathrm{M}$ acetate buffer, $\mathrm{pH} 4.0$, and the corresponding calibration curve plots (B). 
[24,27,29-31], as detailed in Table S2, this approach offered the advantage of being simple and effective, ensuring a wider linear concentration range of response. This wide linear range allows simplifying the sample pre-treating stage, something that is especially important when the concentration level of a given analyte is unknown. As DNA gyrase is targeted by quinolones in general, the response of the biosensor to NOR was also validated, although revealing slightly lower sensitivity and thereby slightly lower affinity. The ability of DNA gyrase to selectively detect quinolones was confirmed by checking the response of the biosensor to AMP and confirming its random response.

The analytical response was also compared to that of an immunosensor prepared similarly. Interestingly, the best analytical features were obtained using the DNA gyrase as biorecognition element. This is likely related to the fact that DNA gyrase sensing layer has more binding points than the antibody sensing layer, in which the antibodies were immobilized first, and their non-specific response was after reduced by incubating BSA (a typical procedure among immunosensors).

Overall, the new design presented herein offers advantageous features in terms of analytical performance and enables readings for different antibiotics among the same group. This concept may be extended to introduce additional insights into the mechanistic action of antibiotics. When in environmental conditions, it is important that the temperature is monitored, as it my influence the electrochemical readings; the system could need additional testing under different temperatures to understand which calibration applies to a given temperature. Regarding reproducibility, it was interesting to note that different biosensing units showed behaviour among each other, especially at the stage of the carbon nanotube modification, which was a common point among all assemblies. In these, the average Rct values was $66.2 \Omega$ and the RSD was $2.7 \%$.

\section{CRediT authorship contribution statement}

Ana R. Cardoso: Investigation, Methodology, Validation, Visualization, Formal analysis, Writing - original draft. Liliana P.T. Carneiro: Investigation, Methodology, Validation. Gustavo Cabral-Miranda: Supervision, Resources, Writing - review \& editing. Martin F. Bachmann: Supervision, Resources, Writing - review \& editing. M. Goreti F. Sales: Conceptualization, Supervision, Formal analysis, Funding acquisition, Resources, Writing - review \& editing.

\section{Declaration of Competing Interest}

The authors declare that they have no known competing financial interests or personal relationships that could have appeared to influence the work reported in this paper.

\section{Acknowledgements}

The authors acknowledge funding from project PTDC/AAG-TEC/ $5400 / 2014$ funded by European funds, through FEDER (European Funding or Regional Development) via COMPETE2020 - POCI (operational program for internationalization and competitively) and by national funding through the National Foundation for Science and Technology, I.P. (FCT). ARC also acknowledge funding to National Foundation for Science and Technology, I.P., through the PhD Grant, SFRH/BD/130107/2017.

\section{Appendix A. Supplementary data}

Supplementary data to this article can be found online at https://doi. org/10.1016/j.cej.2020.128135.

\section{References}

[1] P.H. Axelsen, in: Essentials of Antimicrobial Pharmacology, Springer S, 2001, https://doi.org/10.1385/1592591221.

[2] T.F. Landers, B. Cohen, T.E. Wittum, E.L. Larson, A review of antibiotic use in food animals: perspective, policy, and potential, Public Health Rep. 127 (2012) 4-22, https://doi.org/10.1177/003335491212700103.

[3] J.L. Martinez, Environmental pollution by antibiotics and by antibiotic resistance determinants, Environ. Pollut. 157 (2009) 2893-2902, https://doi.org/10.1016/j. envpol.2009.05.051.

[4] T.P. Van Boeckel, C. Brower, M. Gilbert, B.T. Grenfell, S.A. Levin, T.P. Robinson, A. Teillant, R. Laxminarayan, Global trends in antimicrobial use in food animals, Proc. Natl. Acad. Sci. U.S.A. 112 (2015) 5649-5654, https://doi.org/10.1073/ pnas.1503141112.

[5] E.Y. Klein, T.P. Van Boeckel, E.M. Martinez, S. Pant, S. Gandra, S.A. Levin, H. Goossens, R. Laxminarayan, Global increase and geographic convergence in antibiotic consumption between 2000 and 2015, Proc. Natl. Acad. Sci. U.S.A. 115 (2018) E3463-E3470, https://doi.org/10.1073/pnas.1717295115.

[6] P.J.G. Henriksson, A. Rico, M. Troell, D.H. Klinger, A.H. Buschmann, S. Saksida, M. V. Chadag, W. Zhang, Unpacking factors influencing antimicrobial use in global aquaculture and their implication for management: a review from a systems perspective, Sustain. Sci. 13 (2018) 1105-1120, https://doi.org/10.1007/s11625017-0511-8.

[7] S.A. Kraemer, A. Ramachandran, G.G. Perron, Antibiotic pollution in the environment: from microbial ecology to public policy, Microorganisms 7 (2019) 1-24, https://doi.org/10.3390/microorganisms7060180.

[8] P. Kovalakova, L. Cizmas, T.J. McDonald, B. Marsalek, M. Feng, V.K. Sharma, Occurrence and toxicity of antibiotics in the aquatic environment: a review, Chemosphere 251 (2020) 126351, https://doi.org/10.1016/j. chemosphere.2020.126351.

[9] S. Squadrone, Water environments: metal-tolerant and antibiotic-resistant bacteria, Env. Monit Assess. 192 (2020) 1-12.

[10] T. Nakayama, T.T. Tuyet Hoa, K. Harada, M. Warisaya, M. Asayama, A. Hinenoya, J.W. Lee, T.M. Phu, S. Ueda, Y. Sumimura, K. Hirata, N.T. Phuong, Y. Yamamoto, Water metagenomic analysis reveals low bacterial diversity and the presence of antimicrobial residues and resistance genes in a river containing wastewater from backyard aquacultures in the Mekong Delta, Vietnam, Environ. Pollut. 222 (2017) 294-306, https://doi.org/10.1016/j.envpol.2016.12.041.

[11] K. Yoo, H. Yoo, J. Lee, E.J. Choi, J. Park, Exploring the antibiotic resistome in activated sludge and anaerobic digestion sludge in an urban wastewater treatment plant via metagenomic analysis, J. Microbiol. 58 (2020) 123-130, https://doi.org/ 10.1007/s12275-020-9309-y.

[12] G. Na, Z. Lu, H. Gao, L. Zhang, Q. Li, R. Li, F. Yang, C. Huo, Z. Yao, The effect of environmental factors and migration dynamics on the prevalence of antibioticresistant Escherichia coli in estuary environments, Sci. Rep. 8 (2018) 1-9, https:// doi.org/10.1038/s41598-018-20077-x.

[13] E. O'Flaherty, E. Cummins, Antibiotic resistance in surface water ecosystems: presence in the aquatic environment, prevention strategies, and risk assessment, Hum. Ecol. Risk Assess. 23 (2017) 299-322, https://doi.org/10.1080/ 10807039.2016.1247254.

[14] D.G.J. Larsson, Antibiotics in the environment, Upsala J. Med. Sci. 119 (2014) 108-112, https://doi.org/10.3109/03009734.2014.896438.

[15] P. Grenni, V. Ancona, A. Barra Caracciolo, Ecological effects of antibiotics on natural ecosystems: a review, Microchem. J. 136 (2018) 25-39, https://doi.org/ 10.1016/j.microc.2017.02.006.

[16] A. Goulas, B. Livoreil, N. Grall, P. Benoit, C. Couderc-Obert, C. Dagot, D. Patureau, F. Petit, C. Laouénan, A. Andremont, What are the effective solutions to control the dissemination of antibiotic resistance in the environment? A systematic review protocol, Environ. Evid. 7 (2018), https://doi.org/10.1186/s13750-018-0118-2.

[17] L.T. Sanseverino I, Cuenca A, Loos R, Marinov D, State of the art on the contribution of water to antimicrobial resistance, 2018, https://doi.org/10.2 $760 / 82376$.

[18] P.C. Sharma, A. Jain, S. Jain, R. Pahwa, M.S. Yar, Ciprofloxacin: review on developments in synthetic, analytical, and medicinal aspects, J. Enzyme Inhib. Med. Chem. 25 (2010) 577-589, https://doi.org/10.3109/14756360903373350.

[19] S. Paleti, P.K. Prasad, B.S. Lakshmi, Action and resistance mechanisms of antibiotics: a guide for clinicians, J. Anaesthesiol. Clin. Pharmacol. 33 (2017) 300-305, https://doi.org/10.4103/joacp.JOACP.

[20] V. de Jesus Gaffney, V.V. Cardoso, E. Cardoso, A.P. Teixeira, J. Martins, M. J. Benoliel, C.M.M. Almeida, Occurrence and behaviour of pharmaceutical compounds in a Portuguese wastewater treatment plant: removal efficiency through conventional treatment processes, Environ. Sci. Pollut. Res. 24 (2017) 14717-14734, https://doi.org/10.1007/s11356-017-9012-7.

[21] I.T. Carvalho, L. Santos, Antibiotics in the aquatic environments: a review of the European scenario, Environ. Int. 94 (2016) 736-757, https://doi.org/10.1016/j. envint.2016.06.025.

[22] N. Janecko, L. Pokludova, J. Blahova, Z. Svobodova, I. Literak, Implications of fluoroquinolone contamination for the aquatic environment - a review: fluoroquinolone in the aquatic ecosystem - a review, Environ. Toxicol. Chem. 35 (2016) 2647-2656, https://doi.org/10.1002/etc.3552.

[23] L.R. Guidi, F.A. Santos, A.C.S.R. Ribeiro, C. Fernandes, L.H.M. Silva, M.B.A. Gloria, Quinolones and tetracyclines in aquaculture fish by a simple and rapid LC-MS/MS method, Food Chem. 245 (2018) 1232-1238, https://doi.org/10.1016/j. foodchem.2017.11.094. 
[24] S.A. Lim, M.U. Ahmed, A simple DNA-based electrochemical biosensor for highly sensitive detection of ciprofloxacin using disposable graphene, Anal. Sci. 32 (2016) 687-693, https://doi.org/10.2116/analsci.32.687.

[25] C.M. Manaia, A. Novo, B. Coelho, O.C. Nunes, Ciprofloxacin resistance in domestic wastewater treatment plants, Water Air Soil Pollut. 208 (2010) 335-343, https:// doi.org/10.1007/s11270-009-0171-0.

[26] F. Collin, S. Karkare, A. Maxwell, Exploiting bacterial DNA gyrase as a drug target: current state and perspectives, Appl. Microbiol. Biotechnol. 92 (2011) 479-497, https://doi.org/10.1007/s00253-011-3557-z.

[27] K. Abnous, N.M. Danesh, M. Alibolandi, M. Ramezani, S.M. Taghdisi, A.S. Emrani, A novel electrochemical aptasensor for ultrasensitive detection of fluoroquinolones based on single-stranded DNA-binding protein, Sens. Actuators, B 240 (2017) 100-106, https://doi.org/10.1016/j.snb.2016.08.100.

[28] J. Jaeger, F. Groher, J. Stamm, D. Spiehl, J. Braun, E. Dörsam, B. Suess, Characterization and inkjet printing of an RNA aptamer for paper-based biosensing of ciprofloxacin, Biosensors. 9 (2019) 1-10, https://doi.org/10.3390/ bios9010007.

[29] A.A. Ensafi, A.R. Allafchian, R. Mohammadzadeh, Characterization of $\mathrm{MgFe}_{2} \mathrm{O}_{4}$ nanoparticles as a novel electrochemical sensor: application for the voltammetric determination of ciprofloxacin, Anal. Sci. 28 (2012) 705-710, https://doi.org/ 10.2116/analsci.28.705.

[30] P. Lavaee, N.M. Danesh, M. Ramezani, K. Abnous, S.M. Taghdisi, Colorimetric aptamer based assay for the determination of fluoroquinolones by triggering the reduction-catalyzing activity of gold nanoparticles, Microchim. Acta 184 (2017) 2039-2045, https://doi.org/10.1007/s00604-017-2213-4.

[31] S. Cheraghi, M.A. Taher, H. Karimi-Maleh, E. Faghih-Mirzaei, A nanostructure label-free DNA biosensor for ciprofloxacin analysis as a chemotherapeutic agent: an experimental and theoretical investigation, New J. Chem. 41 (2017) 4985-4989, https://doi.org/10.1039/C7NJ00609H.

[32] A. Pollap, J. Kochana, Electrochemical immunosensors for antibiotic detection, Biosensors 9 (2) (2019) 61, https://doi.org/10.3390/bios9020061.

[33] A.R. Cardoso, A.C. Marques, L. Santos, A.F. Carvalho, F.M. Costa, R. Martins, M.G F. Sales, E. Fortunato, Molecularly-imprinted chloramphenicol sensor with laserinduced graphene electrodes, Biosens. Bioelectron. 124-125 (2019) 167-175, https://doi.org/10.1016/j.bios.2018.10.015.

[34] R. Rauti, M. Musto, S. Bosi, M. Prato, L. Ballerini, Properties and behavior of carbon nanomaterials when interfacing neuronal cells: how far have we come ? Carbon NY 143 (2019) 430-446, https://doi.org/10.1016/j.carbon.2018.11.026.

[35] A.R. Cardoso, G. Cabral-miranda, A. Reyes-sandoval, M.F. Bachmann, Biosensors and Bioelectronics Detecting circulating antibodies by controlled surface modification with specific target proteins: application to malaria 91 (2017) 833-841. https://doi.org/10.1016/j.bios.2017.01.031.

[36] G. Cabral-Miranda, A.R. Cardoso, L.C.S. Ferreira, M.G.F. Sales, M.F. Bachmann, Biosensor-based selective detection of Zika virus specific antibodies in infected individuals, Biosens. Bioelectron. 113 (2018) 101-107, https://doi.org/10.1016/j. bios.2018.04.058.

[37] N.S. Ferreira, M.G.F. Sales, Disposable immunosensor using a simple method for oriented antibody immobilization for label-free real-time detection of an oxidative stress biomarker implicated in cancer diseases, Biosens. Bioelectron. 53 (2014) 193-199, https://doi.org/10.1016/j.bios.2013.09.056.

[38] L. Wang, H. Wu, S. Guo, Study on electrochemical processes of NiO model electrode during the first lithiation/delithiation cycle via electrochemical impedance spectroscopy, Int. J. Electrochem. Sci. 13 (2018) 11491-11501, https://doi.org/10.20964/2018.12.51.

[39] D.A. Harrington, P. van den Driessche, Mechanism and equivalent circuits in electrochemical impedance spectroscopy, Electrochim. Acta 56 (2011) 8005-8013, https://doi.org/10.1016/j.electacta.2011.01.067.

[40] D. Harvey, Modern analytic chemistry, in: K. Kane (Ed.), Mod. Anal. Chem., first ed., McGraw-Hill Higher Education, 2000, p. 797.

[41] K. Jiang, L.S. Schadler, R.W. Siegel, X. Zhang, H. Zhang, M. Terrones, Protein immobilization on carbon nanotubes via a two-step process of diimide-activated amidation, J. Mater. Chem. 14 (2004) 37, https://doi.org/10.1039/b310359e.

[42] A.R. Cardoso, G. Cabral-Miranda, A. Reyes-Sandoval, M.F. Bachmann, M.G. F. Sales, Detecting circulating antibodies by controlled surface modification with specific target proteins: application to malaria, Biosens. Bioelectron. 91 (2017) 833-841, https://doi.org/10.1016/j.bios.2017.01.031.

[43] A.I. López-Lorente, B.M. Simonet, M. Valcárcel, Raman spectroscopic characterization of single walled carbon nanotubes: influence of the sample aggregation state, Analyst 139 (2014) 290-298, https://doi.org/10.1039/ C3AN00642E.

[44] K. Ramakrushna, P. Kumar, L. Suresh, Fabrication of high performance disposable screen printed electrochemical sensor for ciprofloxacin sensing in biological samples, Measurement 127 (2018) 175-186, https://doi.org/10.1016/j. measurement.2018.05.078.

[45] T. Matsunaga, T. Kondo, T. Osasa, A. Kotsugai, Sensitive electrochemical detection of ciprofloxacin at screen-printed diamond electrodes, Carbon NY 159 (2020) 247-254, https://doi.org/10.1016/j.carbon.2019.12.051.

[46] N. Diab, I. Abu-shqair, R. Salim, M. Al-subu, The behavior of ciprofloxacin at a DNA modified glassy carbon electrodes 9 (2014) 1771-1783.

[47] J.L. Arredondo-García, R. Figueroa-Damián, A. Rosas, A. Jáuregui, M. Corral, A. Costa, R.M. Merlos, A. Ríos-Fabra, C.F. Amábile-Cuevas, G.M. Hernández-Oliva, J. Olguín, O. Cardeñosa-Guerra, P. Leal del Rosal, J.A. Leal del Rosal, R.E. Urbina Rodríguez, J. Jaspersen Gastelum, A. Valle Gay, M. Leal, L. Aguirre Chávez, R. Ortega Rosas, D. Akle, A. Torres y Gutiérrez Rubio, R. Orrantia Gradín, J.J. Ceja Rodríguez, C. Lara Pérez Soto, D. Hurley, D. Sotres, R. Ponce de Leon, I. León, R. Villanueva, J.J. Manrique, C. Erdmenger, E. Hidalgo Portillo, J.D. Solano, J. C. Mendoza Roncancio, J.R. Castañeda, B.M. Santos, A.C. Jaramillo-Tobón, F. Cornejo Proaño, N. Paz y Miño, F. Castellanos, B. Gallegos, M. Marcano, I. Arocha, Comparison of short-term treatment regimen of ciprofloxacin versus long-term treatment regimens of trimethoprim/sulfamethoxazole or norfloxacin for uncomplicated lower urinary tract infections: a randomized, multicentre, openlabel, prospective study, J. Antimicrob. Chemother. 54 (2004) 840-843, https:// doi.org/10.1093/jac/dkh414.

[48] S. Teixeira, R.S. Conlan, O.J. Guy, M.G.F. Sales, Novel single-wall carbon nanotube screen-printed electrode as an immunosensor for human chorionic gonadotropin, Electrochim. Acta 136 (2014) 323-329, https://doi.org/10.1016/j. electacta.2014.05.105. 